\title{
Effects of Nonpharmacological Therapies for Diseases of the Elderly
}

\author{
Yoshihisa Koike, Yoko Yamanishi \\ Prefectural University of Hiroshima, Mihara, Japan
}

\author{
Yoshio Kano \\ Kibi International University, Takahashi, Japan
}

\begin{abstract}
Adverse events are a concerning issue related to pharmacotherapy for the elderly. Therefore, we investigated nonpharmacological therapy for diseases of the elderly, which cause fewer adverse events compared with those caused by appropriate pharmacotherapy. The effects of each treatment were examined using the PC12m 3 cell line before clinical study. This cell line comprises mutant cells of the PC12 model neuronal cell line. Treatments from which an effect was expected were clinically studied. VAT (vibroacoustic therapy) provided relaxation effects for elderly nursing home residents and improved depressive symptoms. Steam foot spa treatment resulted in improved cognitive function in geriatric inpatients and a temporary decrease in high blood pressure. The effect of bright light therapy was assessed using PC12m3 cells, and the results were promising for clinical study. However, we did not conduct clinical research because ultraviolet rays were considered to be one of the factors causing the effect.
\end{abstract}

Keywords: PC12m3 cell, VAT (vibroacoustic therapy), steam foot spa treatment, BLT (bright light therapy)

\section{Effects of VAT (Vibroacoustic Therapy)}

\section{Effects on PC12m3 cells}

The PC12m3 cell line is a mutant cell line derived from the neuronal model cell line, PC12, developed by Greene (1977). PC12m3 cells exhibit poor neurite outgrowth in response to NGF (nerve growth factor). Cells treated with NGF show enhanced neurite outgrowth in response to various stimuli such as calcium ionophore, the FK506 immunosuppressant, and heat shock (Kano et al., 2002).

Results. In our study (Koike, 2004), PC12m3 cells were exposed to vibratory sound stimuli at frequencies of $10-200 \mathrm{~Hz}$ for $30 \mathrm{~min}$, followed by treatment with NGF. The results showed that low-frequency vibratory sounds of $20-100 \mathrm{~Hz}$ enhanced neurite outgrowth. The frequency of neurite outgrowth induced by $40-\mathrm{Hz}$, low-frequency, vibratory sound stimuli was approximately three-fold greater than that induced by NGF alone. Activation of p38 MAPK (mitogen-activated protein kinase) plays an important role in neuronal differentiation of PC12m3 cells. Therefore, we examined whether the ability of a low-frequency vibratory sound stimulus to induce neurite outgrowth of $\mathrm{PC} 12 \mathrm{~m} 3$ cells is a reflection of its effect on p38 MAPK activity. The results showed that vibratory sound induced neurite outgrowth via the p38 MAPK signaling pathway in PC12m3 cells.

\section{VAT}

VAT, which was proposed by Skill (1989) in 1989, is attracting increasing attention for its therapeutic

Yoshihisa Koike, Ph.D., professor, Dept. of OT, Faculty of Health and Welfare, Prefectural University of Hiroshima. Yoko Yamanishi, MS., instructor, Dept. of OT, Faculty of Health and Welfare, Prefectural University of Hiroshima. Yoshio Kano, Ph.D., professor,Dept. of OT, School of Health Science, Kibi International University. 
effects. VAT may be a professional challenge for music therapy. Most of its effects are found in the $40-80-\mathrm{Hz}$ range, which is the range in the very center of the vibroacoustic area. In VAT, vibrations are applied directly to the body in the form of low-frequency sinusoid tones in combination with selected music.

Standly (1991) reported that VAT, which combines listening to music with vibrotactile stimulation, results in deeper relaxation effects compared with listening to music alone. In addition, Lundquist, Anderson, and Viding (2009) reported that VAT effectively decreases self-injurious, stereotypic, and destructive behavior among individuals with developmental disabilities.

\section{Clinical Use of VAT}

In our study (Koike, Hoshitani, Tabata, Seki, Nishimura, \& Kano, 2012), VAT provided relaxation effects for elderly nursing home residents and improved depressive symptoms.

Subjects and methods. Fifteen elderly NH (nursing home) residents (five men, 10 women; $86.3 \pm 7.8$ years) with surface psychological symptoms of depression were included. All 15 subjects underwent VAT for 30 min daily for two consecutive weeks, except Saturdays and Sundays.

Results. Depression was significantly ameliorated, as assessed by the DMAS (Dementia Mood Assessment Scale; $p<0.05)$. In addition, depression and sadness were significantly ameliorated, as assessed by items $1-17$ of the DMAS $(p<0.05)$. Significant decreases $(p<0.001)$ in tympanic temperature and pulse rate were observed after VAT (see Table 1). The mean total sleep duration in the second week decreased significantly compared with that during the first week $(p<0.05)$. Furthermore, a significant increase in mean wake time was observed during the second week compared with that during the first week $(p<0.05)$ (see Table 2).

Table 1

Effect of VAT on Cognitive Function, Behavioral Symptoms, and Psychological Symptoms

\begin{tabular}{llll}
\hline \multicolumn{1}{l}{} & $\begin{array}{l}\text { Before VAT } \\
(\text { mean } \pm S D)\end{array}$ & $\begin{array}{l}\text { After VAT } \\
(\text { mean } \pm S D)\end{array}$ & $p$-value \\
\hline MMSE & $19.4 \pm 7.21$ & $19 \pm 7.58$ & 0.577 \\
DBD & $25.93 \pm 10.45$ & $25.26 \pm 13.51$ & 0.554 \\
DMAS (total on 24 items) & $49.66 \pm 16.17$ & $43.8 \pm 17.93^{*}$ & 0.021 \\
Overall dementia severity (DMAS; items 1-17) & $36.66 \pm 11.13$ & $32.93 \pm 14.05^{*}$ & 0.011 \\
Depression and sadness (DMAS; items 18-24) & $12.33 \pm 7.22$ & $10.86 \pm 7.68$ & 0.247 \\
MMSE, Mini Mental State Exam; DBD, Dementia Behavior & & \\
\multicolumn{2}{l}{ Disturbance scale; DMAS, Dementia Mood Assessment Scale } \\
\hline
\end{tabular}

Note. $n=15, \stackrel{*}{p}<0.05$.

Table 2

Effect of VAT on Physiological Responses

\begin{tabular}{llll}
\hline & $\begin{array}{l}\text { Before VAT } \\
(\text { mean } \pm S D)\end{array}$ & $\begin{array}{l}\text { After VAT } \\
(\text { mean } \pm S D)\end{array}$ & $p$-value \\
\hline Tympanic temperature $\left({ }^{\circ} \mathrm{C}\right)$ & $36.46 \pm 0.47$ & $36.31 \pm 0.53^{* * *}$ & 0.00000134 \\
$\mathrm{SpO}_{2}(\%)$ & $95.3 \pm 2.5$ & $95.08 \pm 2.77$ & 0.166 \\
Pulse (beats/min) & $72.28 \pm 9.88$ & $70.66 \pm 9.44^{* * *}$ & 0.0000725 \\
Blood pressure (systolic) $(\mathrm{mmHg})$ & $139.16 \pm 24.96$ & $138.56 \pm 24.17$ & 0.844 \\
Blood pressure (diastolic) $(\mathrm{mmHg})$ & $73.04 \pm 14.43$ & $73.29 \pm 14.81$ & 0.751 \\
\hline
\end{tabular}

Note. $n=150,{ }^{* * *} p<0.001$.

Discussion. Blumenthal reported that aerobic exercise is an effective treatment for depression in the 
elderly, with effects comparable to those of antidepressant drugs (Blumenthal, 1999). In studies on intracellular transduction pathways during aerobic exercise using mouse muscle cells, Akimoto reported that MKK3/MKK6 is activated in the MAPKK (mitogen-activated protein kinases kinase) pathway by aerobic exercise, leading to activation of downstream p38 $\alpha$ MAPK and, eventually, mitochondrial biosynthesis (Akimoto, 2005). In our previous studies in which the effects of low-frequency vibratory sound were investigated using the PC12m3 cell line, we found that MKK3/MKK6 in the MAPKK pathway was activated by low-frequency vibratory sounds of 20-100 Hz, leading to activation of p38 MAPK downstream in the MAPK pathway (Koike, 2004). Overall, these reports suggest that VAT stimulation has an effect similar to that of aerobic exercise by activating p38MAPK.

Falempin and In-Albon (1999) suggested that tendon vibration $(120 \mathrm{~Hz})$ in the rat soleus muscle can be used as a paradigm to counteract the atrophic process observed after hindlimb unloading. In addition, Skill reported that vibroacoustic music $(40-80 \mathrm{~Hz})$ decreases muscle tone and spasms (Skill, 1989). It is possible that the mitigation of depression by VAT in elderly NH residents in this study was caused by vibrotactile stimuli, which represents passive aerobic exercise.

Future well-controlled studies are required to confirm these findings.

\section{Effect of a Steam Foot Spa}

\section{Effect on PC12m3 Cells}

We investigated the role of the p38 MAPK pathway in heat shock-induced neurite outgrowth of PC12 mutant cells with impaired NGF-induced neurite outgrowth (Kano, 2002; Kano, 2001). When cultures of $\mathrm{PC} 12 \mathrm{~m} 3$ cells were exposed to heat stress at $44^{\circ} \mathrm{C}$ for $10 \mathrm{~min}, \mathrm{p} 38$ MAPK activity increased and neurite outgrowth was enhanced (Kano, 2004). Neurite extension was inhibited by the p38 MAPK inhibitor BS203580. Longer heat treatment of PC12m3 cells provoked cell death, which was enhanced by SB203580. These findings suggest that heat-induced activation of 38 MAPK is responsible for neurite outgrowth and survival of $\mathrm{PC} 12 \mathrm{~m} 3$ cells.

In this study, the p38 MAPK pathway induced differentiation of PC12m3 cells because p38 MAPK was activated by heat shock at $44^{\circ} \mathrm{C}$ for $10 \mathrm{~min}$; however, ERK and JNK were not activated under the same heat conditions. Furthermore, $\mathrm{PC} 12 \mathrm{~m} 3$ cells have poor neurite outgrowth despite normal sustained activation of ERK following NGF treatment. Cells respond to elevated temperature by activating p38 MAPK and JNK and by increasing the production of HSP (heat shock proteins) such as HSP27 and 70 as well as Akt (Mearow, Dodge, Rahimtula, \& Yegappan, 2002; Quigney, Gorman, \& Samali, 2003). One target of p38 MAPK is MAPKAP-K2, which phosphorylates HSP27. This, in turn, modulates both the chaperone activity and anti_apoptotic effects of HSP27 (Mearow et al., 2002). HSP70 protects cells from a number of apoptotic stimuli through its chaperone functions of protein folding and assembly (Samali \& Cotter, 1996; J. S. Lee, J. J. Lee, \& Seo, 2005). HSP70 also modulates stress-activated signaling by direct binding to JNK (Park, Lee, Huh, Seo, \& Choi, 2001). Apoptosis was not observed when PC12m3 cells were exposed to heat shock at $44^{\circ} \mathrm{C}$ for 10 min, whereas cell death had already initiated under the same heat conditions in PC12 parental cells. These phenomena may depend on the strong activation of p38 MAPK and HSP following heat-shock treatment of PC12m3 cells.

\section{Clinical Effect of Waon Therapy}

Waon ("Wa" means soothing and "On" means warmth) therapy using an evenly maintained dry sauna 
system at $60^{\circ} \mathrm{C}$, which differs from a traditional sauna, has been studied exclusively by Tei in Japan (Miyauchi et al., 2012; Kuwahata, 2011; Matsushita, Masuda, \& Tei, 2007). Waon therapy warms the entire body in a uniformly heated chamber $\left(60^{\circ} \mathrm{C}\right)$ for $15 \mathrm{~min}$ and maintains the soothing effect outside the sauna for an additional $30 \mathrm{~min}$. Waon therapy is administered once a day (one session) for five days a week and is recommended for more than two weeks or as desired thereafter. Waon therapy has beneficial effects on peripheral arterial disease and is safe, beneficial, and well tolerated by patients with heart failure.

The vasodilator response due to direct heat is lost immediately during Waon therapy. However, cardiac output increases to increase peripheral blood flow, and shear stress occurs repeatedly in the peripheral vascular endothelium. This results in an increase in endothelial NO (nitric oxide) expression.

\section{Waon Therapy for Hamsters}

Fujita et al. (2011) examined the effects of a dry sauna on improvement in cardiac function using TO-2 cardiomyopathic hamsters. These hamsters were treated in a dry sauna system at $39^{\circ} \mathrm{C}$ for $15 \mathrm{~min}$, and the soothing effect was maintained outside the sauna for an additional $20 \min \left(30^{\circ} \mathrm{C}\right)$.

The results suggest that Waon therapy activated the p38 MAPK signaling pathway, leading to the induction HSP27, manganese superoxide dismutase, and HSP32. This induction decreased oxidative stress (4-hydroxy-2-nonenal) and led to improved cardiac function.

\section{Steam Foot Bath in a Patient With CHF (Chronic Heart Failure)}

Higashi, Komamura, and Oda (2009) provided 15-min steam foot baths and gloves heated to $42^{\circ} \mathrm{C}$ for two weeks to a 21-year-old male with severe CHF who required a left ventricular assist device, followed by $30 \mathrm{~min}$ of rest and heat retention in bed. They reported that appendicular thermal therapy was safe in this patient, who was waiting for a heart transplant, and that the procedure may be beneficial for patients with end-stage heart failure.

\section{Clinical Effects of a Steam Foot Spa Treatment}

The results of a VAT pilot study suggest that steam foot spas mitigate cognitive impairment in geriatric inpatients (Koike, H. Kondo, S. Kondo, Takagi, \& Kano, 2013).

Subjects and methods. Geriatric inpatients (13 participants; age, $82.69 \pm 6.53$ years) with cognitive impairment (MMSE score: $18.38 \pm 3.69$ ) were given a 20 -min steam foot spa treatment at $42^{\circ} \mathrm{C}$ for two weeks, five days a week. Physiological indicators such as blood pressure, percutaneous oxygen saturation, pulse, tympanic temperature, and sleep time and efficiency were assessed.

Cognitive function and behavioral and psychological symptoms of dementia were assessed using the MMSE (Mental State Examination), DMAS (Dementia Mood Assessment Scale), and Dementia Behavior Disturbance Scale.

Results. Systolic $(p<0.01)$ and diastolic blood pressure $(p<0.05)$ significantly decreased while tympanic temperature $(p<0.01)$ significantly increased after the steam foot spa compared with those before treatment. A significant improvement was observed in the MMSE score $(p<0.01)$ and in the overall scores for the dementia severity items on the DMAS $(p<0.05)$ (see Table 3 ).

Discussion. The cholinergic nervous system, which projects from the NBM (nucleus basalis of Meynert) in the basal forebrain to the cerebral cortex and from the septal region to the hippocampus, dilates the blood vessels in the cerebral cortex and hippocampus (Sato \& Sato, 1992; Lacombe, Sercombe, Verrecchia, Philipson, MacKenzie, \& Seylaz, 1989). Piché, Uchida, Hara, Aikawa, and Hotta (2010) increased NBM nerve activity 
with somatosensory stimulation and found that acetylcholine is released and blood flow increases within the cerebral cortex. Activation of the nicotinic acetylcholine nervous system enhances the neuroprotective effect to promote increased NGF secretion (Hotta, Kagitani, Kond, \& Uchida, 2009).

In this study, cerebral blood flow increased in geriatric inpatients with an increase in tympanic temperature caused by the steam foot spa treatments. A significant change in the MMSE was observed after the steam foot spa treatment. These results suggest that changes in the MMSE following steam foot spa treatments occurred because of vasodilation of cholinergic neurons.

Table 3

Effect of VAT on Sleep-Wake Rhythm

\begin{tabular}{llll}
\hline & First week & Second week & $p$-value \\
\hline & $($ Mean $\pm S D)$ & $($ Mean $\pm S D)$ & \\
Total sleep time (min) & $626.54 \pm 221.35$ & $599.61 \pm 216.55^{*}$ & 0.0309 \\
Nighttime sleep (min) & $346.41 \pm 174.21$ & $347.8 \pm 172.28$ & 0.707 \\
Nighttime sleep efficiency (\%) & $88.64 \pm 8.33$ & $89.28 \pm 9.76$ & 0.702 \\
Wake time (min) & $813.45 \pm 221.35$ & $838.06 \pm 217.48^{*}$ & 0.0442 \\
\hline
\end{tabular}

Note. $n=75,{ }^{*} p<0.05$.

A significant antihypertensive effect was observed in this pilot study. Although blood pressure decreased significantly after $20 \mathrm{~min}$ of treatment, heart rate did not change. Cholinergic nerves cause vasodilation; however, there was no sustained excitability of these nerves. Therefore, no change in heart rate variability was observed.

The vasodilator response to direct heat is lost immediately during Waon therapy. However, cardiac output increased to increase the peripheral blood flow, and shear stress occurred repeatedly in the peripheral vascular endothelium. As a result, the expression of NO in the endothelium increased.

These results suggest that steam foot spa treatments at an ideal setting of $42^{\circ} \mathrm{C}$ for 20 min potentially improve cognitive function in elderly hospitalized patients with mild to moderate cognitive impairment. In addition, it may lead to improved cardiac function.

\section{BLT (Bright Light Therapy)}

\section{BLT}

An obvious initial candidate for BLT is a patient with seasonal affective disorder (winter depression) (Rosenthal, 1984; James, Wehr, Sack, Parry, \& Rosenthal, 1985). The efficacy of BLT has been supported across a range of mood disorders, including nonseasonal depression and chronic depression (Golden et al., 2005; Kripke, 1998; Goel, Terman, Terman, Macchi, \& Stewart, 2005), manic_depressive psychosis (Deltito, Moline, Pollak, Martin, \& Maremmani, 1991; Sit, Wisner, \& Hanusa, 2007), antepartum and postpartum depression (Oren, Wisner, \& Spinelli, 2002; Wirz-Justice, 2011). Moreover, BLT improves disturbances and insomnia caused by Alzheimer's disease (Ancoli-Israel, Martin, Kripke, Marler, \& Klauber, 2002; Nowak \& Davis, 2011). BLT is usually administered at $\geq 2500$ lux. Although no direct studies comparing different light intensities have been conducted, longer exposure (approximately 2-3 hours) at 2,500 lux or shorter exposure (about $30 \mathrm{~min}$ ) at higher intensities such as 10,000 lux is recommended (Young, 2011).

\section{Effects of UVC Irradiation on PC12m3 Cells}

We have previously investigated cellular damage and differentiation of $\mathrm{PC} 12 \mathrm{~m} 3$ cells caused by UVC 
irradiation (Koike et al., 2006). When PC12m3 cells are exposed to UVC irradiation, the frequency of neurite outgrowth rapidly increases in a dose-dependent manner. The frequency of neurite outgrowth was maximized at $40 \mathrm{~J} / \mathrm{m}^{2}$ of UVC irradiation. The frequency of neurite outgrowth induced by $40 \mathrm{~J} / \mathrm{m}^{2}$ of UVC irradiation was approximately 25 -fold greater than that of neurite outgrowth induced by NGF alone. However, PC12m3 cell survival was inversely proportional to the dose of UVC irradiation.

We examined whether a UVC irradiation stimulus to induce neurite outgrowth of PC12m3 cells is a reflection of its effect on p38 MAPK activity. The results showed that p38 MAPK was strongly activated, whereas JNK and ERK were only weakly activated in PC12m3 cells exposed to UVC. Furthermore, UVC irradiation rapidly and strongly activated cAMP response element-binding in $\mathrm{PC} 12 \mathrm{~m} 3$ cells.

\section{Bright Light Energy}

Fluorescent light provides a source of UVC. UVC usually does not pass through glass, except quartz glass. However, a very small quantity of UVC leaks from a fluorescent tube.

In our preliminary research (date not shown), PC12m3 cells were exposed to a 15,000-lux bright light device at a distance of approximately $15 \mathrm{~cm}$ for $10 \mathrm{~min}$. Then, one group of cells was removed from the UVC and another group of cells was continually exposed. The result showed that when PC12m3 cells were exposed to UVC irradiation, the frequency of neurite outgrowth was significantly higher than that in the group that was not exposed to UVC $(p<0.05)$.

\section{Conclusions}

This was a preliminary study, and we did not conduct a clinical study because UVC is considered to be a factor that affects the BLT effect.

\section{Future Directions}

With regard to the effectiveness of these nonpharmacological treatments presented on this occasion, these researches itself have not gone beyond the scope of preparatory researches, and the effectiveness of these treatments have not yet reached the stage where it can be guaranteed. Thus, it is necessary to acquire further proof of effectiveness through clinical trials.

\section{References}

Akimoto, T., Pohnert, S. C., Li, P., Zhang, M., Gumbs, C., Rosenberg, P. B., ... \& Yan, Z. (2005). Exercise stimulates Pgc-1 $\alpha$ Transcription in skeletal Muscle through activation of the p38 MAPK pathway. J. Biol. Chem, 280, 19587-19593.

Ancoli-Israel, S., Martin, J. L., Kripke, D. F., Marler, M., \& Klauber, M. R. (2002). Effect of light treatment on sleep and circadian rhythms in demented nursing home patients. J. Am. Geriatr Soc., 50, 282-289.

Blumenthal, J. A., Babyak, M. A., Moore, K. A., Craighead, W. E., Herman, S., Khatri, P., ... Krishnan, K. R. (1999). Effects of exercise training on older patients with major depression. Arch Intern Med., 159, 2349-2356.

Deltito, J. A., Moline, M., Pollak, C., Martin, L. Y., \& Maremmani, I. (1991). Effects of phototherapy on non-seasonal unipolar and bipolar depressive spectrum disorders. J. Affect Disord, 23(4), 231-237.

Falempin, M., \& In-Albon, S. F. (1999). Influence of brief daily tendon vibration on rat soleus muscle in non-weight-bearing situation. J. Appl Physiol, 87, 3-9.

Fujita, S., Ikeda, Y., Miyata, M., Shinsato, T., Kubozono, T., Kuwahata, S.... Tei, C. (2011). Effect of Waon therapy on oxidative stress in chronic heart failure. Circ J., 75(2), 348-356.

Goel, N., Terman, M., Terman, J. S., Macchi, M. M., \& Stewart, J. W. (2005). Controlled trial of bright light and negative air ions for chronic depression. Psychol Med., 35(7), 945-955. 
Golden, R. N., Gaynes, B. N., Ekstrom, R. D., Hamer, R. M., Jacobsen, F. M. et al. (2005). The efficacy of light therapy in the treatment of mood disorders: a review and meta-analysis of the evidence. Am. J. Psychiatry, 162, 656-862.

Green, L. A. (1977). A quantitative bioassay for nerve growth factor (NGF) activity employing a clonal pheochromocytoma cell line. Brain Res, 133, 350-353.

Higashi, H., Komamura, K., \& Oda, N. (2009). Experience of appendicular thermal therapy applied to a patient with a left ventricular assist device awaiting heart transplantation. J. Cardiol, 53, 301-305.

Hotta, H., Kagitani, F., Kond, M., \& Uchida, S. (2009). Basal forebrain stimulation induces NGF secretion in ipsilateral parietal cortex via nicotinic receptor activation in adult, but not aged rats. Neurosci Res, 63(2), 122-128.

James, S. P., Wehr, T. A., Sack, D. A., Parry, B. L., \& Rosenthal, N. E. (1985). Treatment of seasonal affective disorder with light in the evening. Br. J. Psychiatry, 147, 424-428.

Kano, Y., Hiragami, F., Kawamura, K., Kimata, Y., Nakagiri, S., Poffenberger, C. K.,... Gomita. (2002). Immunosuppressant FK506 induces sustained activation of MAP kinase and promotes neurite outgrowth in PC12 mutant cells incapable of differentiating. Cell Struct Funct, 27(5), 393-398.

Kano, Y., Nakagiri, S., Nohno, T., Hiragami, F., Kawamura, K., Kadota, M.... Furuta, T. (2004). Heat shock induces neurite outgrowth in PC12m3 cells via the p38 mitogen-activated protein kinase pathway. Brain Res, 1026(2), 302-306.

Kano, Y., Nohno, T., Takahashi, R., Hasegawa, T., Hiragami, F., Kawamura, K., ... Sugiyama, T. (2001). cAMP and calcium ionophore induce outgrowth of neuronal processes in PC12 mutant cells in which nerve growth factor-induced outgrowth of neuronal processes is impaired. Neurosci Lett, 303(1), 21-24.

Kripke, D. F. (1998). Light treatment for nonseasonal depression: speed, efficacy, and combined treatment. J. Affect Disord, 49(2), 109-117.

Koike, Y., Hoshitani, M., Tabata, Y., Seki, K., Nishimura, R., \& Kano, Y. (2012). Effects of vibroacoustic therapy on elderly nursing home residents with depression. J. Phys. Ther. Sci., 24, 291-294.

Koike, Y., Iwamot, S., Kimata, Y., Nohno, T., Hiragami, F., Kawamura, K, ... Kano, Y. (2004). Low-frequency vibratory sound induces neurite outgrowth in $\mathrm{PC} 12 \mathrm{~m} 3$ cells in which nerve growth factor-induced neurite outgrowth is impaired. Tiss. Cult. Res. Commun, 23, 81-90.

Koike, Y., Iwamoto, S., Fukumoto, Y., Hiragami, F., Kawamura, K., Motoda, H., \& Kano, Y. (2006). UVC irradiation induces neurite outgrowth in $\mathrm{PC} 12 \mathrm{~m} 3$ cells via the p38 mitogen_activated protein kinase and transcription factor CREB pathway. Tiss. Cult. commun, 25, 129-136.

Koike, Y., Kondo, H., Kondo, S., Takagi, M., \& Kano, Y. (2013). Effect of a steam foot spa on geriatric inpatients with cognitive impairment: A pilot study. Clin Interv Aging, 8, 543-548.

Kuwahata, S., Miyata, M., Fujita, S., Kubozono, T., Shinsato, T., Ikeda, Y... Tei, C. (2011). Effect of Waon therapy on oxidative stress in chronic heart failure. J. Cardiol, 57(1), 100-106.

Lacombe, P., Sercombe, R., Verrecchia, C., Philipson, V., MacKenzie, E. T., \& Seylaz, J. (1989). Cortical blood flow increases induced by stimulation of the substantia innominata in the unanesthetized rat. Brain Res, 491(1), 1-14.

Lee, J. S., Lee, J. J., \& Seo, J. S. (2005). HSP70 deficiency results in activation of c-Jun N-terminal kinase, extracellular signal-regulated kinase, and caspase-3 in hyperosmolarity-induced apoptosis. J. Biol Chem, 280, 6634-6641.

Lundquist, L. O., Anderson, G., \& Viding, J. (2009). Effect of vibroacoustic music on challenging haviors in individual with autism and developmental disabilities. Res Autism Spectr Disord, 3, 390-400.

Matsushita, K., Masuda, A., \& Tei, C. (2007). Waon therapy improves peripheral arterial disease. J. Am. Coll Cardiol, 50(22), 2169-2171.

Mearow, K. M., Dodge, M. E., Rahimtula, M., \& Yegappan, C. (2002). Stress-mediated signaling in PC12 cells-The role of the small heat shock protein, Hsp27, and Akt in protecting cells from heat stress and nerve growth factor withdrawal. $J$. Neurochem, 83(2), 452-462.

Miyauchi, T., Miyata, M., Ikeda, Y., Akasaki, Y., Hamada, N., Shirasawa, T....Tei, C. (2012). Waon therapy upregulates Hsp90 and leads to angiogenesis through the Akt-endothelial nitric oxide synthase pathway in mouse hindlimb ischemia. Circ J., 76(7), 1712-1721.

Nowak, L., \& Davis, J. (2011). Qualitative analysis of therapeutic light effects on global function in Alzheimer's disease. West J. Nurs Res, 33(7), 933-952.

Oren, D. A., Wisner, K. L., \& Spinelli, M. (2002). An open trial of morning light therapy for treatment of antepartum depression. Am. J. Psychiatry, 159(4), 666-669. 
Park, H. S., Lee, J. S., Huh, S. H., Seo, J. S., \& Choi, E. J. (2001). Hsp72 functions as a natural inhibitory protein of c-Jun N-terninal kinase. EMBO J., 20, 446-456.

Piché, M., Uchida, S., Hara, S., Aikawa, Y., \& Hotta, H. (2010). Modulation of somatosensory-evoked cortical blood flow changes by GABAergic inhibition of the nucleus basalis of Meynert in urethane-anaesthetized rats. J. Physiol, 588, 2163-2171.

Quigney, D. J., Gorman, A. M., \& Samali, A. (2003). Heat shock protects PC12 cells against MPP+toxicity. Brain Res, 993(1-2), 133-139.

Rosenthal, N. E., Sack, D. A., Gillin, J. C., Lewy, A. J., Goodwin, F. K. et al. (1984). Seasonal affective disorder: A description of the syndrome and preliminary findings with light therapy. Arch Gen Psychiatry, 41(1), 72-80.

Samali, A., \& Cotter, T. G. (1996). Heat shock proteins increase resistance to apoptosis. Exp Cell Res, 223, 163-170.

Sato, A., \& Sato, Y. (1992). Regulation of regional cerebral blood flow by cholinergic fibers originating in the basal forebrain. Neurosci Res, 14(4), 242-274.

Sit, D., Wisner, K. L., \& Hanusa, B. H. (2007). Light therapy for bipolar disorder: A case series in women. Bipolar Disord, 9(8), 918-927.

Skill, O. (1989). Vibro acoustic therapy. Music therapy, 8, 61-77.

Standly, J. M. (1991). The effect of vibrotactail and auditory stimuli on perception of comfort, heat reat, and peripheral finger temperature. Journal of music Therapy, 28(3), 120-134.

Wirz-Justice, A., Bader, A., Frisch, U., Stieglitz, R. D., Alder, J. et al. (2011). A randomized, double-blind, placebo-controlled study of light therapy for antepartum depression. J. Clin Psychiatry, 72(7), 986-993.

Young, S. N. (2011). Bright light for nonseasonal depression? J. Psychiatry Neurosci, 36(5), 37-38. 